\title{
Infant feeding decisions and behaviours among low-income smoke-exposed women: timing and change during pregnancy
}

\author{
Patricia Markham Risica ${ }^{1,2,3, *}$ and Kristen McCausland ${ }^{2}$ \\ 'Department of Behavioral and Social Sciences, Brown School of Public Health, Brown University, Providence, RI, \\ USA: ${ }^{2}$ Department of Epidemiology, Brown School of Public Health, Brown University, Box G-121S, Providence, RI \\ 02912, USA: ${ }^{3}$ Center for Health Equity Research, Brown School of Public Health, Brown University, Providence, RI, USA
}

Submitted 21 June 2016: Final revision received 16 May 2017: Accepted 16 June 2017: First published online 3 August 2017

\begin{abstract}
Objective: The present study aimed to describe change in feeding intentions and predictors of breast-feeding intentions during the course of pregnancy.

Design: Analysis of prospectively collected data from a larger randomized controlled trial of a health education intervention to reduce environmental smoke exposure among women during and after pregnancy.

Setting: Participants were recruited from prenatal clinics, but all further communication occurred with participating women living in the community.

Subjects: Low-income, adult women ( $n$ 399) were interviewed during the 16th and 32nd week of pregnancy to ascertain prenatal feeding intentions and breastfeeding knowledge, attitudes and self-efficacy. Characteristics of women by infant feeding intention were assessed along with differences in intention from 16 to 32 weeks of pregnancy and feeding behaviours after delivery. Differences in psychosocial variables between women of different intention for infant feeding were measured. Women in each category of feeding intention were assessed for changes in psychosocial factors by eventual infant feeding behaviour.

Results: Feeding intention early in pregnancy was strongly, but not consistently, associated with feeding intention late in pregnancy, feeding initiation and later feeding patterns. Over one-third of women who were undecided at 16 weeks' gestation or earlier initiated breast-feeding. Increases in knowledge and improvement in time, social factors and social support barriers were found among those who exclusively breast-fed.

Conclusions: Results indicate that feeding decisions may change during pregnancy. Determining when women make feeding decisions during their pregnancy warrants more research. Interventions to increase breast-feeding intentions should target knowledge, self-efficacy and barriers.
\end{abstract}

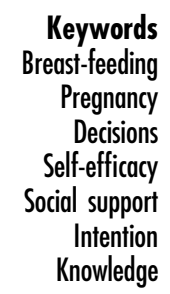

Breast milk, the preferred source of nutrition for most infants $^{(1-3)}$, is associated with well-documented health benefits for both mother and child. Increased breast-feeding could save the USA billions of dollars and hundreds of lives $^{(4)}$. In the USA, breast-feeding initiation among babies born in 2011 was $79 \%^{(5)}$, compared with the national goal of $82 \%{ }^{(6)}$. Although the majority of women initiate breast-feeding, breast-feeding duration and exclusivity fall well short of national goals ${ }^{(2)}$. Only $49 \%$ of recent mothers breast-fed for at least 6 months as recommended ${ }^{(5)}$, compared with the goal of $61 \%{ }^{(6)}$; and further, only $19 \%$ of infants were breast-fed exclusively at 6 months ${ }^{(5)}$ compared with the goal of $26 \%$ nationally ${ }^{(6)}$.

Breast-feeding decisions are influenced by various social and cognitive factors, including knowledge about the benefits of breast-feeding, attitudes regarding the time commitment and potential embarrassment, perceived social support and self-efficacy ${ }^{(7-13)}$. In many cases, infant feeding decisions are made prior to or very early in pregnancy ${ }^{(11,12)}$. However, little is documented about the timing of feeding intentions and changes throughout pregnancy.

The purpose of the present study was to examine changes in breast-feeding-related knowledge, attitudes and self-efficacy, and prenatal breast-feeding intentions, among a low-income smoke-exposed population during the course of pregnancy, who were participants of a smoking cessation and environmental tobacco smoke avoidance intervention study. Furthermore, the study also examined how changes in knowledge, barriers and self-efficacy may influence early infant feeding behaviours 
among women who had not yet decided on a feeding plan early in their pregnancies.

\section{Methods}

The present study assessed ancillary data to a larger randomized controlled trial of a health education intervention to reduce environmental tobacco smoke exposure among women during and after pregnancy. Pregnant women were recruited from three prenatal clinics in Rhode Island, USA that serve mostly low-income women: St. Joseph's Hospital, Memorial Hospital of Rhode Island (MHRI) and the Women's Primary Care Center at Women and Infants' Hospital (WIH). The study was approved by the institutional review boards of Brown University and each of the clinical sites listed.

To determine eligibility, staff screened prenatal patients at the time of their initial prenatal appointment. To be eligible for the study, women were required to speak English, to be at least 18 years of age, to be currently smoking, recently quit or exposed to environmental tobacco smoke, to be no further than 16 weeks' gestation in a singleton pregnancy, and to have access to a working telephone and VCR/DVD player. After the initial screening, interviewers used computer-assisted telephone interviews at 16 weeks of pregnancy or earlier to obtain consent and conduct a baseline survey, followed by another at 32 weeks' gestation to ascertain prenatal feeding intentions as well as knowledge, attitudes and self-efficacy related to breast-feeding. An additional telephone interview was conducted at 12 weeks' postpartum to determine actual breast-feeding behaviours.

Among the 1314 eligible participants identified through screening, 64\% completed the baseline survey and were randomized to the parent randomized controlled trial ( $n$ 847). Of these, 246 participants were excluded from the present analysis for not completing the 32-week gestational interview and one participant was excluded for missing data on the primary outcome, prenatal feeding intentions. Of the remaining 600 women from the study, 399 were asked the knowledge and attitude questions, leaving 399 in the analytic sample.

The intervention videos being tested included smokerelated messages tailored to the needs of the participant, but presented within an overall theme of prenatal health. Both study groups received newsletters containing healthy pregnancy messages, but only the intervention group received messages regarding smoking cessation or environmental tobacco smoke avoidance. Healthy infant feeding and breast-feeding were included in the video and newsletters very minimally for both intervention groups. Infant feeding attitude, intention or behavioural variables were not different between intervention groups, so data from both groups were included in these analyses.

Outcome variables for the current analysis were prenatal feeding intention and actual feeding behaviours.
Participants' self-reported prenatal feeding intention was queried at both baseline (approximately 12-16 weeks' gestation) and 32 weeks' gestation, with response categories of 'exclusive breast-feeding', 'breast-feeding and formula in combination', 'exclusive formula' and 'undecided'. Responses coded by the interviewer as 'don't know' were re-coded as 'undecided'. Given the known benefits of any breast-feeding and the small number of women planning to exclusively breast-feed, a dichotomous breast-feeding intention variable ('exclusive breast-feeding or breast-feeding and formulafeeding' $v$. 'exclusive formula-feeding or undecided') was also examined.

Infant feeding initiation at delivery and infant feeding at $30 \mathrm{~d}$ were queried at 12 weeks' postpartum. Women were asked to describe their current feeding practices with choices of 'breast-feeding only', 'breast-feeding and formula' and 'formula only'. Also, women were asked if they ever breast-fed; if yes, they were asked the age of the baby when he or she was first fed formula or some other food other than breast milk. Women who breast-fed for at least $1 \mathrm{~d}$ and initiated formula or another type of food supplementation later than $1 \mathrm{~d}$ were categorized as 'initiating breast-feeding'. Women who never attempted to breast-feed or breast-fed for less than $1 \mathrm{~d}$ and initiated formula/other food supplementation within the first day were categorized as 'exclusive formula-feeding'.

Feeding at $30 \mathrm{~d}$ was similarly determined. Women who reported exclusive breast-feeding at the time of the 12-week survey or women who initiated formula or other food when the baby was $30 \mathrm{~d}$ or older were both considered to be 'exclusively breast-feeding' at $30 \mathrm{~d}$ postpartum. Among women who initiated breast-feeding and breast-fed for at least $30 \mathrm{~d}$, those who additionally initiated formula or other food supplementation prior to $30 \mathrm{~d}$ were considered to be 'breast- and formula- (mixed) feeding' at $30 \mathrm{~d}$ postpartum. Women who never breast-fed or stopped breast-feeding completely before $30 \mathrm{~d}$ were considered to be 'exclusively formula-feeding'.

Measures of breast-feeding knowledge, attitudes and self-efficacy adapted from previous studies were conducted at baseline and at the 32 -week survey ${ }^{(7,8)}$. The response options (true/false) used in the original work were modified to a five-point Likert scale ranging from 'agree a lot' to 'agree a little', 'neither agree nor disagree', 'disagree a little' and 'disagree a lot'. Responses coded by interviewers as 'don't know', which likely represented legitimate ambivalence or lack of information, were recoded to the 'neither agree nor disagree' category.

Responses were assigned numerical values ranging from -2 to +2 , where +2 represented the strongest response in the direction favouring breast-feeding support. A global index was created by averaging the responses from each of the eighteen individual items created by Mitra et al. ${ }^{(8)}$ (referred to as the 'Mitra index' hereafter). A higher overall Mitra index score represented more favourable breastfeeding-related thoughts or attitudes. Mitra index subscales 
were created and labelled as the following factors: 'knowledge', 'self-efficacy', 'embarrassment barriers', 'social and time barriers' and 'social support barriers'. Cronbach's $\alpha$ was estimated for each of the overall Mitra index and subscale scores. The overall Mitra index exhibited strong internal consistency with a raw score of $0 \cdot 76$.

Sociodemographic characteristics were queried at the baseline gestational interview including mother's age, race/ethnicity, educational attainment, employment status, household income, marital status, country of birth, native language and years lived in the USA. Parity was ascertained from the hospital discharge records pertaining to participants' deliveries.

Differences in baseline sociodemographic characteristics by feeding intention were examined using $\chi^{2}$ analyses for all categorical variables. ANOVA models were constructed to test for differences in mean Mitra index scores by breast-feeding intention category at baseline. Demographic variables associated with breast-feeding intention at baseline were included in the models. Significance tests were calculated for pairwise comparisons of Mitra index scores using $t$ tests corrected for multiple comparisons using the Tukey-Kramer procedure.

A subgroup analysis was conducted among categories of baseline feeding intention (undecided, any breast-feeding (exclusive or mixed) and exclusive formula-feeding) to examine differences between baseline and 32-week Mitra index scores within each category of breast-feeding initiation (exclusive formula-feeding and breast-feeding). All scores and sub-scores were assessed as having a Shapiro-Wilkes test of $\geq 0.89$, indicating that there is extremely low probability that these values are not normally distributed. Paired $t$ tests were calculated to assess differences between baseline and 32-week overall Mitra index and subscale scores. ANOVA models were constructed for the Mitra index score and sub-scores at baseline and 32 weeks' gestation to assess differences between feeding initiation groups with potentially confounding demographic variables (as in models of baseline values above) included in each model (n 103 for full models). Data were analysed using the statistical software package SAS version 9.4.

\section{Results}

Participants were distributed fairly evenly between the age groups of $<21$ years (28\%), 21-25 years (38\%) and $>25$ years (34\%). The majority of the sample was comprised of young adult women ( $66 \%$ of women were 25 years of age or younger). Overall, $40 \%$ of participants self-identified as non-Hispanic White, $13 \%$ as non-Hispanic Black, $27 \%$ as Hispanic and $19 \%$ as 'other' or identified with two or more racial groups; $16 \%$ were born outside the USA. Over a third of the sample $(36 \%)$ had not completed high school or earned a general education degree. Only $13 \%$ of participants reported a household annual income of greater than
\$US 30000 ; and 58\% were not employed full- or part-time. Approximately $46 \%$ of the sampled women were not with a partner (had never been married or were currently divorced or separated); and equal proportions had previously delivered one or more live birth (Table 1).

\section{Baseline prenatal feeding intentions}

At baseline, nearly half (44\%) of the sample reported an intention to breast-feed in some capacity with $18 \%$ planning to breast-feed exclusively and $26 \%$ reporting an intention to both breast-feed and formula-feed. Just under a quarter of participants planned to only feed formula, and about a third had not yet decided on a feeding plan. Feeding intention differed by age, education, racial/ethnic groups, nativity and having had a previous live birth (Table 1).

Women who planned to breast-feed were more likely to be younger, having their first child, Hispanic, be born outside the USA, be higher educated and speak Spanish based on bivariate analyses. Women who were undecided about how they would feed their baby were more likely to be younger, of more than one racial or ethnic group, be high-school educated, be born in the USA, speak English and have no previous live births.

\section{Knowledge and attitudes about breast-feeding}

The baseline Mitra index scores differed by feeding intention (Table 2). Women intending to exclusively breast-feed had higher overall Mitra index and subscale scores than women intending to exclusively formula-feed or women who were undecided about feeding plans. With the exception of knowledge sub-scores, women planning to exclusively breast-feed had similar subscale scores to women planning to breast-feed either exclusively or in combination with formula. Women who were undecided had similar knowledge sub-scores compared with women planning to combination feed, but similar embarrassment barriers sub-scores to women planning to exclusively formula-feed. Otherwise, women who were undecided had overall Mitra index, self-efficacy, time and social barriers, and social support barriers scores that were higher than those of women planning to exclusively formula-feed, but lower than those of women planning to breast-feed exclusively or combined with formula.

\section{Change in prenatal feeding intentions}

Most women were consistent from early in pregnancy ( 16 weeks) to late pregnancy (32 weeks) in their intended feeding method (Fig. 1). Of those planning early in pregnancy to exclusively breast-feed, 58.9\% were still planning to exclusively breast-feed later in pregnancy, but $31.5 \%$ were then planning to breast-feed in combination with feeding formula. Of those planning initially to feed in combination, $74.0 \%$ were still planning to feed in combination later in pregnancy, while $12.5 \%$ were then planning to exclusively breast-feed. Women planning to exclusively formula-feed 
Table 1 Sample characteristics by feeding intention at 16 weeks' gestation or earlier among low-income smoke-exposed women ( $n$ 399) recruited from three prenatal clinics in Rhode Island, USA, February 2006-June 2009

\begin{tabular}{|c|c|c|c|c|c|c|c|}
\hline Characteristic & $n$ & $\%$ & $\begin{array}{c}\text { Exclusive } \\
\text { breast-feeding }\end{array}$ & $\begin{array}{l}\text { Breast-feeding and } \\
\text { formula-feeding }\end{array}$ & $\begin{array}{c}\text { Exclusive } \\
\text { formula-feeding }\end{array}$ & Undecided & $P$ value \\
\hline $\begin{array}{l}\text { Overall }(n) \\
\%\end{array}$ & 399 & & $\begin{array}{l}73 \\
18 \cdot 3\end{array}$ & $\begin{array}{l}104 \\
26 \cdot 1\end{array}$ & $\begin{array}{l}94 \\
23 \cdot 6\end{array}$ & $\begin{array}{l}128 \\
32 \cdot 1\end{array}$ & \\
\hline Age category & & & & & & & $<0.05$ \\
\hline$<21$ years & 112 & $28 \cdot 1$ & $30 \cdot 1$ & 29.8 & $16 \cdot 0$ & $34 \cdot 4$ & \\
\hline $21-25$ years & 151 & 37.8 & $37 \cdot 0$ & 37.5 & $36 \cdot 2$ & $39 \cdot 8$ & \\
\hline$>25$ years & 136 & $34 \cdot 1$ & 32.9 & $32 \cdot 7$ & $47 . \overline{9}$ & $25 \cdot 8$ & \\
\hline Race/ethnicity & & & & & & & $<0.001$ \\
\hline White, non-Hispanic & 160 & $40 \cdot 1$ & $49 \cdot 3$ & 27.9 & $45 \cdot 7$ & $40 \cdot 6$ & \\
\hline Black, non-Hispanic & 53 & 13.3 & 5.5 & $17 \cdot 3$ & 14.9 & $13 \cdot 3$ & \\
\hline Hispanic & 109 & $27 \cdot 3$ & 31.5 & 41.4 & 14.9 & $26 \cdot 7$ & \\
\hline Other/more than one & 77 & $19 \cdot 3$ & $13 \cdot 7$ & 13.5 & 24.5 & 23.4 & \\
\hline Education & & & & & & & $<0.001$ \\
\hline Less than high school & 144 & $36 \cdot 1$ & $27 \cdot 4$ & $31 \cdot 1$ & $52 \cdot 1$ & $34 \cdot 1$ & \\
\hline High-school graduate/GED & 143 & 35.8 & 42.5 & 28.2 & 34.0 & 40.5 & \\
\hline At least some college/technical school & 109 & $27 \cdot 3$ & $30 \cdot 1$ & $40 \cdot 8$ & $13 \cdot 8$ & $25 \cdot 4$ & \\
\hline Employment status & & & & & & & 0.51 \\
\hline Employed full- or part-time & 179 & 44.9 & 42.5 & $50 \cdot 0$ & 39.8 & $46 \cdot 1$ & \\
\hline Not employed full- or part-time & 219 & 57.5 & 57.5 & $50 \cdot 0$ & $60 \cdot 2$ & 53.9 & \\
\hline Household annual income & & & & & & & 0.73 \\
\hline$<\$$ US 10000 & 165 & 41.4 & $41 \cdot 1$ & $47 \cdot 1$ & $40 \cdot 7$ & $38 \cdot 6$ & \\
\hline \$US $10000-30000$ & 129 & $32 \cdot 3$ & $27 \cdot 4$ & $31 \cdot 7$ & $36 \cdot 3$ & 33.9 & \\
\hline$>\$$ US 30000 & 51 & $12 \cdot 8$ & $15 \cdot 1$ & 13.5 & 11.0 & $12 \cdot 6$ & \\
\hline Don't know & 50 & 12.5 & $16 \cdot 4$ & $7 \cdot 7$ & $12 \cdot 1$ & $15 \cdot 0$ & \\
\hline Partner status & & & & & & & 0.13 \\
\hline Never married/divorced/separated & 184 & $46 \cdot 1$ & $38 \cdot 9$ & $45 \cdot 6$ & $56 \cdot 4$ & $44 \cdot 1$ & \\
\hline Married/engaged/living with a significant other & 212 & 52.9 & $61 \cdot 1$ & 54.4 & $43 \cdot 6$ & $55 \cdot 9$ & \\
\hline Nativity & & & & & & & $<0.001$ \\
\hline Born in the USA & 335 & $84 \cdot 0$ & 84.9 & $71 \cdot 2$ & 93.6 & $86 \cdot 7$ & \\
\hline Other & 64 & $16 \cdot 0$ & $15 \cdot 1$ & 28.9 & $6 \cdot 4$ & $13 \cdot 3$ & \\
\hline Years lived in USA & & & & & & & 0.12 \\
\hline$\leq 5$ years & 10 & $15 \cdot 6$ & 18.2 & 23.3 & 0.0 & 5.9 & \\
\hline $6-15$ years & 20 & 31.3 & $18 \cdot 2$ & $36 \cdot 7$ & 0.0 & $41 \cdot 2$ & \\
\hline$>15$ years & 34 & 53.1 & $63 \cdot \overline{6}$ & $40 \cdot 0$ & $100 \cdot 0$ & 52.9 & \\
\hline \multicolumn{8}{|l|}{ Native language } \\
\hline English & 315 & 78.9 & $78 \cdot 1$ & $67 \cdot 3$ & $86 \cdot 2$ & $83 \cdot 6$ & $<0.05$ \\
\hline Spanish & 60 & $15 \cdot 0$ & $16 \cdot 4$ & $26 \cdot 0$ & 7.5 & $10 \cdot 9$ & \\
\hline Other & 24 & $6 \cdot 1$ & 5.5 & $6 \cdot 7$ & $6 \cdot 4$ & 5.5 & \\
\hline Previous live births (multiparous) & & & & & & & $<0.01$ \\
\hline Yes & 184 & $46 \cdot 1$ & $43 \cdot 7$ & 49.5 & 65.9 & $42 \cdot 5$ & \\
\hline No & 185 & $46 \cdot 6$ & $56 \cdot 3$ & 50.5 & $34 \cdot 1$ & 57.5 & \\
\hline
\end{tabular}

GED, general education degree.

Individual $n$ may not add to the total sample size due to missing values.

Table 2 Mean baseline overall Mitra index and subscale scores for prenatal knowledge, attitudes and self-efficacy related to breast-feeding by feeding intention at 16 weeks' gestation or earlier among low-income smoke-exposed women $(n 399)$ recruited from three prenatal clinics in Rhode Island, USA, February 2006-June 2009

\begin{tabular}{|c|c|c|c|c|c|c|c|c|c|}
\hline \multirow[b]{2}{*}{ Measure } & \multicolumn{2}{|c|}{$\begin{array}{c}\text { Exclusive } \\
\text { breast-feeding ( } n \text { 73) }\end{array}$} & \multicolumn{2}{|c|}{$\begin{array}{c}\text { Breast-feeding and } \\
\text { formula-feeding }(n \text { 150) }\end{array}$} & \multicolumn{2}{|c|}{$\begin{array}{c}\text { Exclusive } \\
\text { formula-feeding ( } n \text { 96) }\end{array}$} & \multicolumn{2}{|c|}{$\begin{array}{l}\text { Undecided } \\
\quad(n \text { 80) }\end{array}$} & \multirow[b]{2}{*}{$P$ value } \\
\hline & Mean & SE & Mean & SE & Mean & SE & Mean & SE & \\
\hline $\begin{array}{l}\text { Overall Mitra index } \\
\text { Mitra index subscales }\end{array}$ & $1.08^{c, d}$ & 0.08 & $0.94^{c, d}$ & 0.07 & $0.02^{a, b, d}$ & 0.08 & $0.51^{a, b, c}$ & 0.07 & $<0.0001$ \\
\hline $\begin{array}{l}\text { Knowledge } \\
\text { Self-efficacy } \\
\text { Embarrassment barriers } \\
\text { Time and social barriers } \\
\text { Social support barriers }\end{array}$ & $\begin{array}{l}1.31^{\mathrm{b}, \mathrm{c}, \mathrm{d}} \\
1.45^{\mathrm{c}, \mathrm{d}} \\
0.25^{\mathrm{c}, \mathrm{d}} \\
1.09^{\mathrm{c}, \mathrm{d}} \\
1.42^{\mathrm{c}, \mathrm{d}}\end{array}$ & $\begin{array}{l}0.11 \\
0.12 \\
0.16 \\
0.11 \\
0.11\end{array}$ & $\begin{array}{l}0.96^{\mathrm{a}, \mathrm{c}} \\
1.31^{\mathrm{c}, \mathrm{d}} \\
0.07^{\mathrm{c}, \mathrm{d}} \\
1.27^{\mathrm{c}, \mathrm{d}} \\
1.20^{\mathrm{c}, \mathrm{d}}\end{array}$ & $\begin{array}{l}0.10 \\
0.11 \\
0.13 \\
0 \cdot 10 \\
0.10\end{array}$ & $\begin{array}{r}0.12^{\mathrm{a}, \mathrm{b}, \mathrm{d}} \\
-0.09^{\mathrm{a}, \mathrm{b}, \mathrm{d}} \\
-0.48^{\mathrm{a}, \mathrm{b}} \\
0.31^{\mathrm{a}, \mathrm{b}, \mathrm{d}} \\
0.26^{\mathrm{a}, \mathrm{b}, \mathrm{d}}\end{array}$ & $\begin{array}{l}0.11 \\
0.12 \\
0.16 \\
0.11 \\
0.11\end{array}$ & $\begin{array}{c}0.71^{\mathrm{a}, \mathrm{c}} \\
0.71^{\mathrm{a}, \mathrm{b}, \mathrm{c}} \\
-0.36^{\mathrm{a}, \mathrm{b}} \\
0.73^{\mathrm{a}, \mathrm{b}, \mathrm{c}} \\
0.85^{\mathrm{a}, \mathrm{b}, \mathrm{c}}\end{array}$ & $\begin{array}{l}0 \cdot 10 \\
0 \cdot 11 \\
0 \cdot 14 \\
0 \cdot 10 \\
0 \cdot 10\end{array}$ & $\begin{array}{l}<0.0001 \\
<0.0001 \\
<0.0001 \\
<0.0001 \\
<0.0001\end{array}$ \\
\hline
\end{tabular}

Least-square means adjusted for age category, race, education, nativity, native language and previous live birth. Index scores range from -2 to +2 , with greater means indicating more favourable scores. Significance of noted pairwise comparisons were corrected for multiple comparisons using Tukey-Kramer's procedure $(P<0.05)$.

${ }^{a}$ Significant difference between women intending to exclusively breast-feed.

${ }^{\mathrm{b}}$ Significant difference between women intending to breast-feed and formula-feed in combination.

'Significant difference between women intending to exclusively formula-feed.

${ }^{\mathrm{d}}$ Significant difference between women who were undecided. 


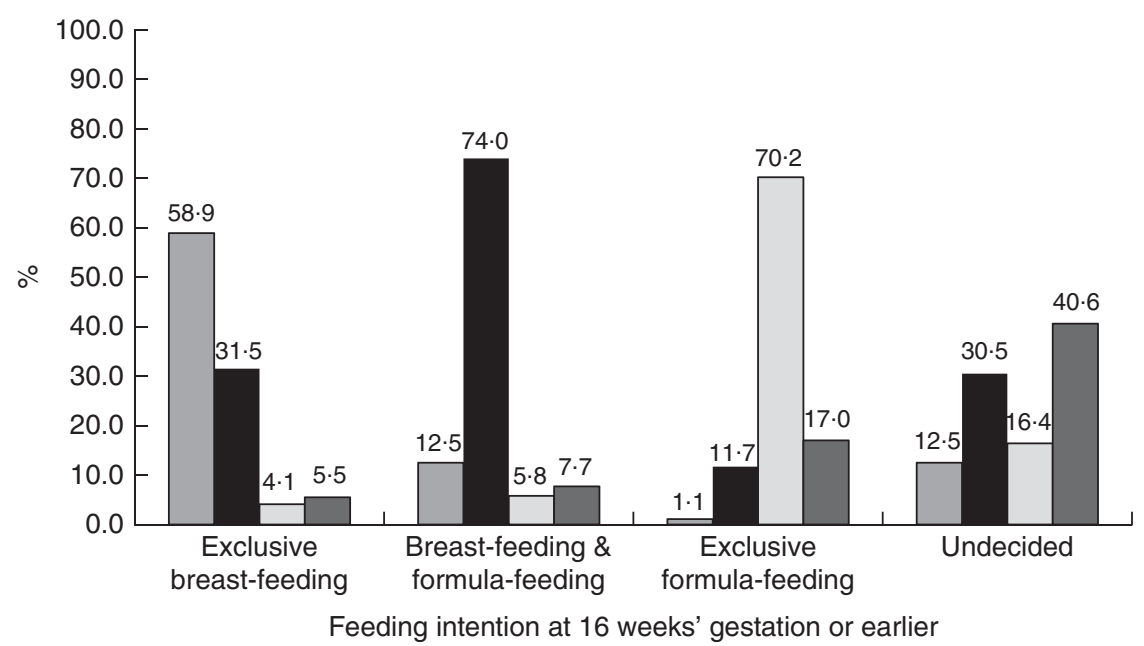

Fig. 1 Feeding intentions at 32 weeks' gestation ( $\square$, exclusive breast-feeding; $\square$, breast-feeding and formula-feeding; $\square$, exclusive formula-feeding; $\square$, undecided) by intentions reported at 16 weeks' gestation or earlier among low-income smoke-exposed women ( $n$ 399) recruited from three prenatal clinics in Rhode Island, USA, February 2006-June 2009

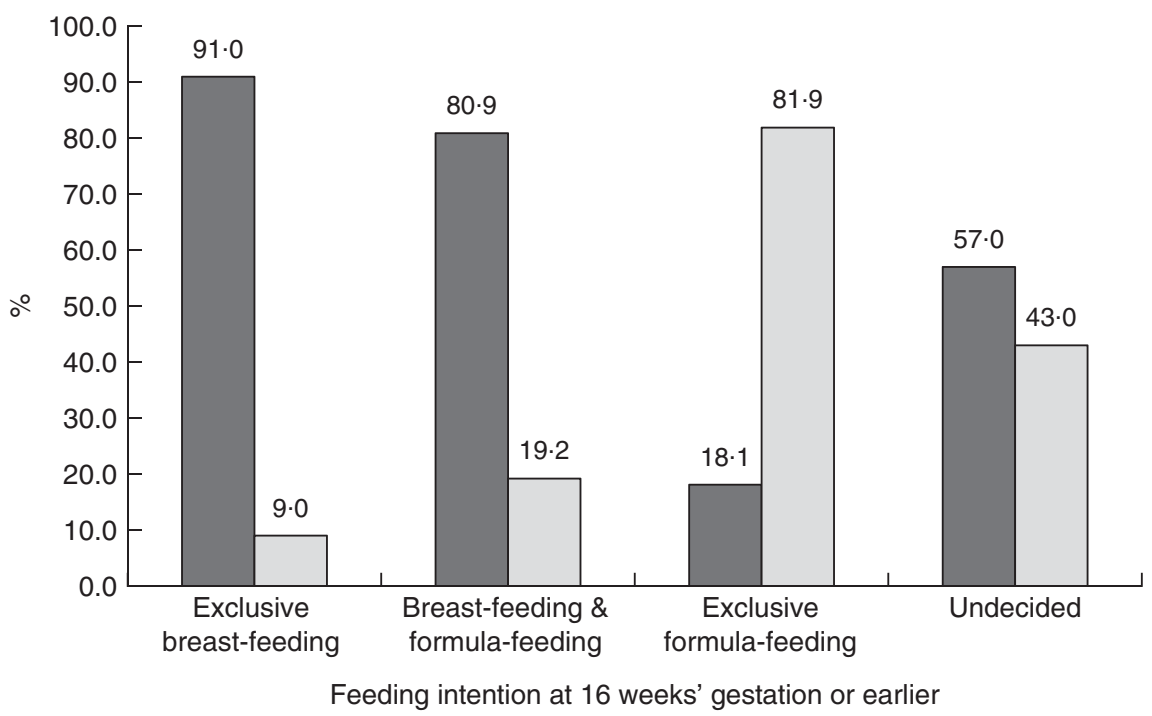

Fig. 2 Infant feeding at delivery ( $\square$, any breast-feeding; $\square$, exclusive formula-feeding) by intentions reported at 16 weeks' gestation or earlier among low-income smoke-exposed women ( $n$ 399) recruited from three prenatal clinics in Rhode Island, USA, February 2006-June 2009

early in pregnancy were very likely $(70 \cdot 2 \%)$ to still plan to exclusively formula-feed at 32 weeks' gestation, although $11.7 \%$ had decided to feed formula in combination with breast-feeding and $17 \cdot 0 \%$ were newly undecided. The highest proportion (40.6\%) of women who were undecided about their plan early in pregnancy was still undecided at 32 weeks' gestation. Almost one-third of those undecided were newly planning to both breast-feed and feed formula, compared with $16.4 \%$ who had decided to exclusively formula-feed and $12.5 \%$ who decided to exclusively breast-feed.

\section{Postpartum infant feeding behaviours}

Breast-feeding initiation was observed by feeding intentions reported at baseline (Fig. 2). Of women planning at baseline to exclusively breast-feed, $91.0 \%$ initiated breast-feeding, compared with $80.9 \%$ of women planning at baseline to combination feed. Of women who planned at baseline to exclusively formula-feed, $18.1 \%$ initiated at least some breast-feeding. Additionally, $57.0 \%$ of those who were initially undecided initiated breast-feeding.

By $30 \mathrm{~d}$ postpartum, feeding patterns showed that early many women completed their initial infant feeding plan, although supplementation occurred across all feeding intention groups (Fig. 3). Over $75 \%$ of women planning to exclusively breast-feed were still breast-feeding at $30 \mathrm{~d}$ postpartum, with $47 \cdot 6 \%$ still exclusively breast-feeding. Just over $65 \%$ of women planning to combination feed were still breast-feeding at $30 \mathrm{~d}$ postpartum, with $29.9 \%$ exclusively breast-feeding. Over $12 \%$ of women planning to exclusively formula-feed were breast-feeding at $30 \mathrm{~d}$ 


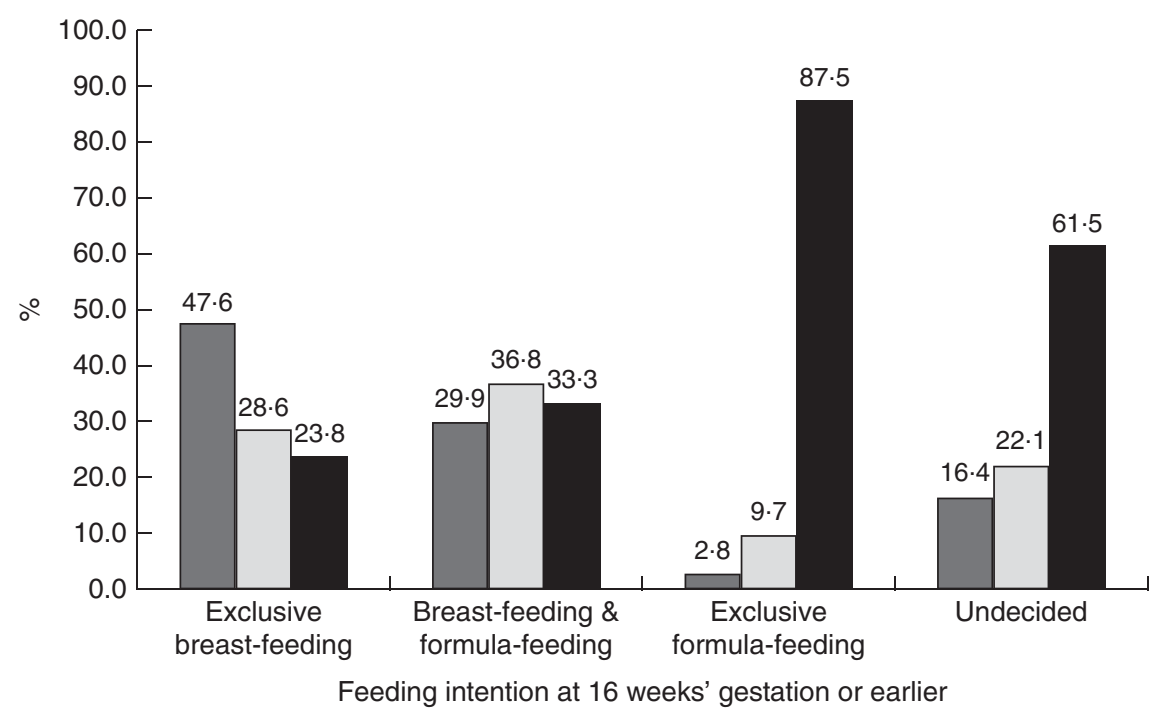

Fig. 3 Infant feeding at $30 \mathrm{~d}$ ( $\square$, exclusive breast-feeding; $\square$, breast-feeding and formula-feeding; $\square$, exclusive formula-feeding) by intentions reported at 16 weeks' gestation or earlier among low-income smoke-exposed women ( $n$ 399) recruited from three prenatal clinics in Rhode Island, USA, February 2006-June 2009

postpartum, most of whom (9.7\%) were also feeding formula. Also, less than half (38.5\%) of women who were undecided about their feeding method were breastfeeding in some capacity at $30 \mathrm{~d}$ after delivery. Of those initially undecided, $16 \cdot 4 \%$ were exclusively breast-feeding and $22.1 \%$ were feeding both breast milk and formula, with an additional $61.5 \%$ exclusively formula-feeding.

Knowledge, attitude and self-efficacy changes were assessed from baseline to 32 weeks for all categories of feeding intention at baseline, by the actual initial feeding method reported (Table 3). Women who were undecided about feeding plans early in pregnancy, but initiated breast-feeding, significantly increased their overall Mitra index score from 0.60 to $0.85(P<0.0001)$, whereas women who initiated exclusive formula-feeding had no change in the overall Mitra index score. At 32 weeks, women who initiated exclusive breast-feeding reported higher overall Mitra index score than women who initiated exclusive formula-feeding $(P=0 \cdot 0022)$.

Among the initially undecided group, no differences in any of the baseline subscale scores were found between women who breast-fed and those who did not. Knowledge changed only among women who initiated breastfeeding (0.71 to $1.03, P=0.0009)$, while no change in knowledge was observed for women who later formulafed exclusively. Similarly, self-efficacy for breast-feeding increased significantly among women who later breast-fed (0.93 to $1 \cdot 14, P=0.0520)$. At 32 weeks, no differences were found between feeding initiation groups in knowledge sub-scores, although self-efficacy was significantly higher among women who breast-fed compared with exclusive formula feeders $(P=0 \cdot 0020)$.

Embarrassment barriers sub-scores were similar at 32 weeks for both feeding groups, and did not change significantly for either group. Time and social barriers sub-scores increased from baseline to 32 weeks for women who breast-fed ( 0.93 to $1.22, P=0.0018)$, but did not change for those who exclusively formula-fed. Social support barriers sub-scores increased from baseline to 32 weeks among women who initiated any breast-feeding (0.84 to $1 \cdot 10, P=0.0351)$. At 32 weeks, exclusive formula feeders had lower time and social barriers (0.86 v. 0.86, $P=0 \cdot 0018)$ and social support barriers sub-scores than women who breast-fed (0.74 v. 1.10, $P=0.0351)$.

Among those who intended to breast-feed, no differences in baseline Mitra scores or sub-scores were found between those who initiated breast-feeding and those who did not. At 32 weeks' gestation, women who would initiate breast-feeding scored higher on the overall Mitra index compared with those who would later feed formula $(1.16 v .0 .85, P<0.05)$ as well as higher on the knowledge $(1.23 v .0 .88, P<0.05)$, self-efficacy $(1.43 v .1 \cdot 06, P<0.05)$ and social support barriers $(1.35$ v. $0.97, \quad P<0.05)$ subscales. Among women who intended to feed formula, no differences in Mitra index scores were found between those who initiated breast-feeding compared with those who initiated exclusive formula-feeding.

Changes in Mitra index scores were found for women who intended at baseline to breast-feed and initiated breast-feeding. The overall Mitra index score increased from 1.06 to $1.16(P=0.0057)$. Average embarrassment barriers sub-score increased for this group $(0.28 v .0 .53$, $P=0.0040)$ and the increase in knowledge sub-score also approached statistical significance (1.11 v. 1.23, $P=0.0667)$. No changes were found for those who intended to breast-feed but initiated exclusive formulafeeding.

Among women who intended to feed formula, those who initiated breast-feeding averaged an increase in overall Mitra index score from 0.06 to $0.51(P=0.0370)$, 


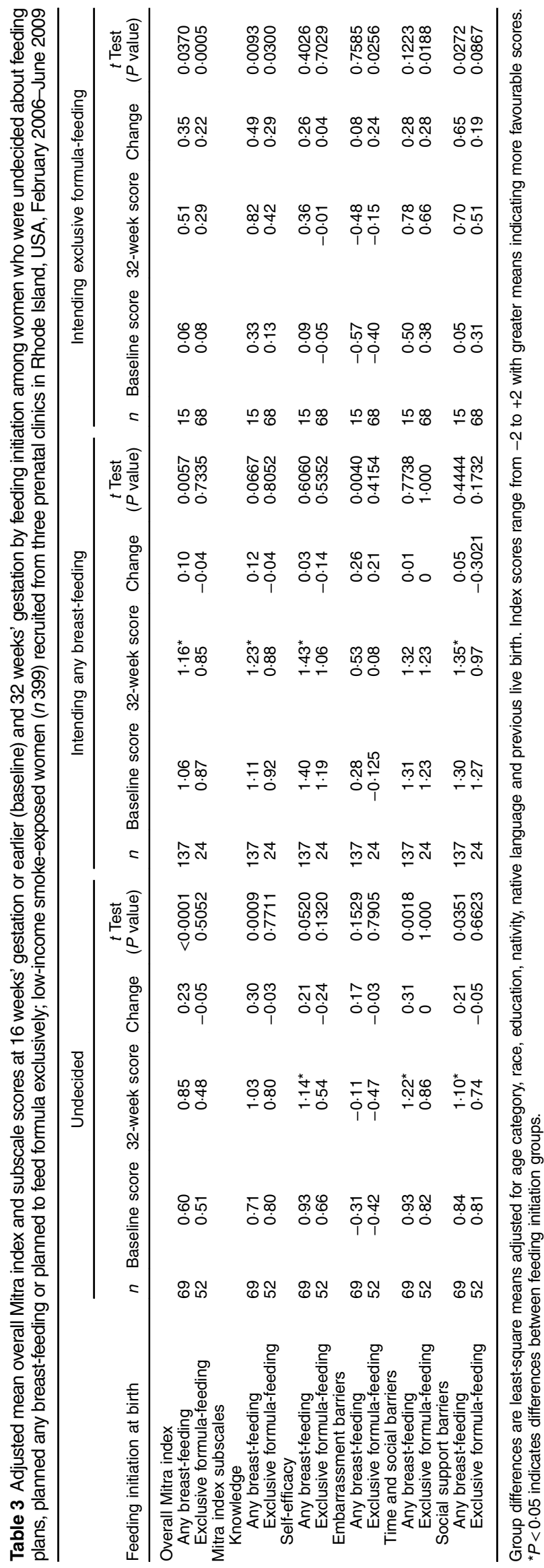

whereas those who initiated exclusive formula-feeding increased from 0.08 to $0.23(P=0.0005)$. Both groups also increased mean knowledge sub-scores, with those who initiated breast-feeding increasing from 0.33 to 0.82 $(P=0.0093)$ and those who initiated exclusive formulafeeding from 0.13 to $0.42(P=0.0300)$.

Women who intended to formula-feed and initiated formula-feeding increased in embarrassment $(-0.40$ to $-0.15, P=0.0256)$ and time and social barriers sub-scores (0.38 to $0.66, P=0.0188)$. Women who intended to formula-feed but initiated breast-feeding increased in social support barriers sub-score (0.05 to $0.70, P=0.0272)$.

\section{Discussion}

The present data demonstrate that infant feeding decisions for many women evolve throughout pregnancy, although a large proportion of women are able to state their intention early and most followed through on that intention. However, almost a third (32\%) of women in this sample were still undecided at 16 weeks of pregnancy and $20 \%$ at 32 weeks. In fact, $41 \%$ of those undecided at baseline were still undecided at 32 weeks. Additionally, breast-feeding was initiated by $57 \%$ of those who were at baseline undecided along with $18 \%$ of those intending to formula-feed (Fig. 2). Exclusive and mixed breast-feeding was continued at $30 \mathrm{~d}$ among 3 and $10 \%$, respectively, of those who were intending to exclusively formula-feed as well as among 16 and $22 \%$, respectively, of those who were undecided. Although others have asserted that most feeding decisions are made before pregnancy ${ }^{(12)}$ or early in pregnancy ${ }^{(11)}$, the current study identifies that a small proportion, but important group of women, decide how they will feed their infant during pregnancy, some very soon before delivery. Additionally, we document the plasticity of breast-feeding plans during pregnancy among those with seemingly firm plans. These findings highlight opportunities for breastfeeding education, support and motivation of low-income women throughout pregnancy.

These opportunities for enhancing breast-feeding support are further underscored by changes in the knowledge, attitudes and self-efficacy Mitra index sub-scores documented among these groups. Women who are undecided early in pregnancy are still likely to be undecided late in pregnancy or plan to combine feeding breast milk and formula. Increases in knowledge, self-efficacy, social support barriers, and time and social barriers subscale scores were all independently associated with eventual decisions to breast-feed among those who were undecided at baseline. Increases in embarrassment barriers sub-scores among women intending to breast-feed, and in social support barriers sub-scores among women planning not to breast-feed, were associated with breast-feeding initiation. Scores for every factor among the undecided group were higher for women who breast-fed, compared with values for women who exclusively 
formula-fed, and knowledge, self-efficacy and social support sub-scores were higher at 32 weeks among those who intended to breast-feed for those who breast-fed compared with the small group that did not initiate breast-feeding. Scores were lower among the group intending to formulafeed compared with other women, and not different between groups based on feeding initiation.

Education and motivation may also be key factors in exclusive breast-feeding. Exclusive breast-feeding is recommended as exclusivity provides added health protections over breast milk mixed with formula ${ }^{(1)}$. Exclusivity is recommended until at least 4 months of age by the $\mathrm{WHO}^{(3)}$ and the US Breastfeeding Committee ${ }^{(14)}$, but the USA ( $41 \%$ at 3 months and $19 \%$ at 6 months) falls far short of the national exclusivity goals of $46 \%$ at 3 months and $26 \%$ at 6 months. The present study identifies knowledge as the biggest factor separating women who planned early to breast-feed exclusively from women planning to supplement with formula; however, in addition to knowledge, other subscales, such as self-efficacy, social support barriers, and time and social barriers, increased among women who were initially undecided, but who initiated breast-feeding.

While the present study did not examine the independent sociodemographic factors associated with breast-feeding exclusivity, other researchers have identified age ${ }^{(15-17)}$; race, ethnicity or place of birth $^{(16-19)}$; marital status or family structure $^{(15,17)}$; smoking status ${ }^{(15)}$; mental and emotional health $^{(15)}$; and support from a partner ${ }^{(20,21)}$ or parent ${ }^{(22,23)}$ as predictors of exclusivity. Additionally, identified psychosocial predictors of exclusivity duration include attitude ${ }^{(24-26)}$, social support ${ }^{(26)}$, and birthing situation and attendants ${ }^{(16,27,28)}$. While emphasis is appropriately placed in health messaging motivating women to breast-feed, room should be made to emphasize in clinical discussion or public health messaging a plan to breast-feed exclusively, addressing barriers and decreases in motivation that might lead to supplementation. Stuebe and Bonuck identified prenatal knowledge and comfort with breast-feeding in a social setting to be associated with intention to breast-feed exclusively ${ }^{(29)}$. However, emphasis on these constructs beyond recent calls to action ${ }^{(2)}$ may improve the focus on exclusivity in clinical and public health messaging.

Further underscoring the need for emphasis on exclusivity, our research found strong initiation; but feeding patterns at $30 \mathrm{~d}$ demonstrated fairly common early formula supplementation, even among women intending to exclusively breast-feed. Prenatal emphasis on exclusivity planning while intentions are still being formed or confirmed may be useful. However, exclusive breastfeeding was reported by some women planning to combination feed, and even by some planning to exclusively formula-feed. This signifies that although decisions may seem to be firm, opportunities to help women choose to exclusively breast-feed still exist even for women who seem to be past that choice.
Among the undecided group, the changes in the Mitra index sub-scores observed between intention and initiation show that increasing knowledge, self-efficacy and both social support and time and social barriers were associated with breast-feeding. More than half of the initially undecided participants and almost one in five planning to formula-feed initiated breast-feeding. However, $15 \%$ of those planning to initiate breast-feeding did not follow through, reporting exclusively feeding formula. These constructs of knowledge, self-efficacy, and attending to social support and time and social barriers, should be combined in health education during pregnancy, and a plan for exclusivity addressing possible future barriers or concerns may prove to be the most successful.

The current study's findings are limited by the study design. The population was smoke-exposed and recruited from clinics serving low-income women in the north-eastern USA, so these data may not be representative of all pregnant women in the USA. As a secondary analysis of a larger randomized controlled study, the intervention was not designed to and did not target breast-feeding as an outcome. The sample size for some variables, including breast-feeding at $30 \mathrm{~d}$ postpartum, was limited. Also, the time points for interviews and measures were not chosen to optimally address breast-feeding study objectives, and required recall of specific feeding and supplementation behaviours sometimes weeks or months after the occurrence. Furthermore, all explanatory variables may not have been measured. For instance, previous research has found a relationship of initiation of breast-feeding with previous breast-feeding experience, parity ${ }^{(30)}$ and participation in the Special Supplemental Nutrition Program for Women, Infants, and Children ${ }^{(31)}$, none of which were addressed in the current analysis. Lastly, the type of analysis conducted was not able to be adjusted for multiple comparisons, but the number of analyses may lead to the conclusion that some significant results were due to chance alone.

While acknowledging these limitations, the present prospective study recorded breast-feeding intentions in real time at baseline and late in pregnancy. Breast-feeding behaviours at delivery and $30 \mathrm{~d}$ postpartum were collected at 12 weeks' postpartum, which introduced some potential for recall bias, but this was reduced compared with studies asking in even later questionnaires. However, these results provide an important insight into women most at risk for not breast-feeding, including low-income women ${ }^{(32-34)}$ and women who are smoke-exposed ${ }^{(15,35-38)}$, so the study makes a potentially important contribution to the breast-feeding and health education literature. Further research should identify when feeding intentions become finalized (i.e. later time points). Also, prenatal planning factors associated with meeting the recommendations for 6 months of exclusive breast-feeding should be identified and tested.

Based on clear evidence that, for many, infant feeding decisions are not firm even late into pregnancy, efforts to encourage women to breast-feed exclusively should be 
maintained throughout pregnancy with special emphasis on education about the attributes of breast-feeding as well as the benefits of exclusivity for at least 4 months.

\section{Acknowledgements}

Acknowledgements: The authors are grateful to the mothers who volunteered to participate in this study, as well as for the partnerships with Drs Maureen Phipps and Donna Parker, which made recruitment possible. They would also like to thank the Baby's Breath study team members: Leslie Strolla, Norma Hardy, Catherine McMahon, Hilda Castillo, Yasmil Montes, Lauren Hubbard, Lizette Muriel, Dierdre Murphy and Kristen Delayo. Special thanks are owed to Thomas Lasater, PhD (deceased), the originator of the study. Financial support: This research was supported by the National Heart, Lung, and Blood Institute (NHLBI; grant number R01 HL070947-O1A). The NHLBI had no role in the design, analysis or writing of this article. Conflict of interest: None. Authorship: P.M.R. formulated the research questions, designed the study, and oversaw all conduct of the study and analysis. K.M. conducted analyses and contributed to interpretation and manuscript preparation. Ethics of buman subject participation: The study was approved by the institutional review boards of Brown University, St. Joseph's Hospital, the Memorial Hospital of Rhode Island (MHRI) and the Women's Primary Care Center at Women and Infants' Hospital (WIH).

\section{References}

1. Section on Breastfeeding (2012) Breastfeeding and the use of human milk. Pediatrics 129, e827-e841.

2. US Department of Health and Human Services (2011) The Surgeon General's Call to Action to Support Breastfeeding. Washington, DC: US DHHS, Office of the Surgeon General.

3. World Health Organization \& UNICEF (2003) Global Strategy for Infant and Young Child Feeding, http://apps.who. int/iris/bitstream/10665/42590/1/9241562218.pdf (accessed July 2017).

4. Bartick M \& Reinhold A (2010) The burden of suboptimal breastfeeding in the United States: a pediatric cost analysis. Pediatrics 125, 1048-1056.

5. Centers for Disease Control and Prevention, Department of Nutrition, Physical Activity and Obesity, National Center for Chronic Disease Prevention and Health (2014) Breastfeeding Among US Children Born 2001-2011, CDC National Immunization Survey. http://www.cdc.gov/BREASTFEEDING/ DATA/NIS_data/ (accessed August 2014).

6. US Department of Health and Human Services, Office of Disease Prevention and Health Promotion (2014) Healthy People 2020. http://www.healthypeople.gov/2020/ topicsobjectives2020/objectiveslist.aspx?topicId=26 (accessed August 2014).

7. Khoury AJ, Moazzem SW, Jarjoura CM et al. (2005) Breastfeeding initiation in low-income women: Role of attitudes, support, and perceived control. Womens Health Issues 15, 64-72.

8. Mitra AK, Khoury AJ, Hinton AW et al. (2004) Predictors of breastfeeding intention among low-income women. Matern Child Health J 8, 65-70.
9. Brown A, Raynor P \& Lee M (2011) Healthcare professionals' and mothers' perceptions of factors that influence decisions to breastfeed or formula feed infants: a comparative study. J Adv Nurs 67, 1993-2003.

10. Bunik M, Clark L, Zimmer LM et al. (2006) Early infant feeding decisions in low-income Latinas. Breastfeed Med $\mathbf{1}$, 225-235.

11. Arora S, McJunkin C, Wehrer J et al. (2000) Major factors influencing breastfeeding rates: mother's perception of father's attitude and milk supply. Pediatrics 106, E67.

12. Losch M, Dungy CI, Russell D et al. (1995) Impact of attitudes on maternal decisions regarding infant feeding. J Pediatr 126, 507-514.

13. Wagner CL \& Wagner MT (1999) The breast or the bottle? Determinants of infant feeding behaviors. Clin Perinatol 26, 505-525.

14. Labbok M \& Taylor E (2008) Achieving Exclusive Breastfeeding in the United States: Findings and Recommendations. Washington, DC: US Breastfeeding Committee.

15. Jones JR, Kogan MD, Singh GK et al. (2011) Factors associated with exclusive breastfeeding in the United States. Pediatrics 128, 1117-1125.

16. Newton KN, Chaudhuri J, Grossman X et al. (2009) Factors associated with exclusive breastfeeding among Latina women giving birth at an inner-city baby-friendly hospital. J Hum Lact 25, 28-33.

17. Phillips G, Brett K \& Mendola P (2011) Previous breastfeeding practices and duration of exclusive breastfeeding in the United States. Matern Child Health J 15, 1210-1216.

18. Belanoff CM, McManus BM, Carle AC et al. (2012) Racial/ ethnic variation in breastfeeding across the US: a multilevel analysis from the National Survey of Children's Health, 2007. Matern Child Health J 16, Suppl. 1, S14-S26.

19. Sussner KM, Lindsay AC \& Peterson KE (2008) The influence of acculturation on breast-feeding initiation and duration in low-income women in the US. J Biosoc Sci 40, 673-696.

20. Hinic K (2016) Predictors of breastfeeding confidence in the early postpartum period. J Obstet Gynecol Neonatal Nurs 45, 649-660.

21. Rempel LA, Rempel JK \& Moore KC (2016) Relationships between types of father breastfeeding support and breastfeeding outcomes. Matern Child Nutr (Epublication ahead of print version).

22. Kitano N, Nomura K, Kido M et al. (2016) Combined effects of maternal age and parity on successful initiation of exclusive breastfeeding. Prev Med Rep 3, 121-126.

23. Fleurant E, Schoeny M, Hoban R et al. (2016) Barriers to human milk feeding at discharge of very-low-birth-weight infants: maternal goal setting as a key social factor. Breastfeed Med 12, 20-27.

24. Bai Y, Middlestadt SE, Peng CY et al. (2010) Predictors of continuation of exclusive breastfeeding for the first six months of life. J Hum Lact 26, 26-34.

25. Bai Y, Wunderlich SM \& Fly AD (2011) Predicting intentions to continue exclusive breastfeeding for 6 months: a comparison among racial/ethnic groups. Matern Child Health J 15, 1257-1264.

26. de Jager E, Skouteris H, Broadbent J et al. (2013) Psychosocial correlates of exclusive breastfeeding: a systematic review. Midwifery 29, 506-518.

27. McDonald SD, Pullenayegum E, Chapman B et al. (2012) Prevalence and predictors of exclusive breastfeeding at hospital discharge. Obstet Gynecol 119, 1171-1179.

28. Semenic S, Loiselle C \& Gottlieb L (2008) Predictors of the duration of exclusive breastfeeding among first-time mothers. Res Nurs Health 31, 428-441.

29. Stuebe AM \& Bonuck K (2011) What predicts intent to breastfeed exclusively? Breastfeeding knowledge, attitudes, and beliefs in a diverse urban population. Breastfeed Med $\mathbf{6}$, 413-420. 
30. Holbrook KE, White MC, Heyman MB et al. (2013) Maternal sociodemographic characteristics and the use of the Iowa Infant Attitude Feeding Scale to describe breastfeeding initiation and duration in a population of urban, Latina mothers: a prospective cohort study. Int Breastfeeding J 8, 7 .

31. Ziol-Guest KM \& Hernandez DC (2010) First- and secondtrimester WIC participation is associated with lower rates of breastfeeding and early introduction of cow's milk during infancy. J Am Diet Assoc 110, 702-709.

32. Haslam C, Lawrence W \& Haefeli K (2003) Intention to breastfeed and other important health-related behaviour and beliefs during pregnancy. Fam Pract 20, 528-530.

33. Kronborg H \& Vaeth M (2004) The influence of psychosocial factors on the duration of breastfeeding. Scand J Public Health 32, 210-216.

34. Simard I, O'Brien HT, Beaudoin A et al. (2005) Factors influencing the initiation and duration of breastfeeding among low-income women followed by the Canada prenatal nutrition program in 4 regions of Quebec. J Hum Lact 21, 327-337.

35. Donath SM \& Amir LH (2004) The relationship between maternal smoking and breastfeeding duration after adjustment for maternal infant feeding intention. Acta Paediatr 93, $1514-1518$

36. Goldade K, Nichter M, Adrian S et al. (2008) Breastfeeding and smoking among low-income women: results of a longitudinal qualitative study. Birth 35, 230-240.

37. Leung GM, Ho LM \& Lam TH (2002) Maternal, paternal and environmental tobacco smoking and breast feeding. Paediatric Perinat Epidemiol 16, 236-245.

38. Weiser TM, Lin M, Garikapaty V et al. (2009) Association of maternal smoking status with breastfeeding practices: Missouri, 2005. Pediatrics 124, 1603-1610. 